\title{
DESPESAS PÚBLICAS: ANÁLISE DAS DESPESAS COM PESSOAL NOS MUNICÍPIOS DA REGIÃO VIII DO ZONEAMENTO SÓCIO ECONÔMICO ECOLÓGICO - MT
}

\author{
Jandher Jonnathan de Araújo ${ }^{1}$ \\ Magno Alves Ribeiro ${ }^{2}$
}

\section{RESUMO}

Por meio do presente artigo, objetiva-se analisar a situação das despesas com pessoal dos municípios da Região VIII do Zoneamento Sócio Econômico Ecológico (ZSEE) - MT entre os anos de 2007 a 2010, para trazer aos munícipes e leitores de forma simplificada, comparações das despesas com pessoal do poder executivo com os limites estabelecidos pela Lei de Responsabilidade Fiscal (LRF) e com a média de toda a região. Esta pesquisa classifica-se como bibliográfica e documental, pela utilização dos dados, materiais já publicados e fontes primárias. A metodologia utilizada no tratamento do problema é quantitativa e qualitativa, também é de natureza descritiva, pois exibe o comportamento das despesas públicas com o campo de pesquisa delimitado. Dentre o período pesquisado em todos os anos, pelo menos um município da região esteve acima do Limite Prudencial da LRF. Tangará da Serra sempre esteve acima da média de gastos da região, enquanto Denise manteve abaixo da média durante os três primeiros períodos.

Palavras-chave: Limite de gastos. Lei de Responsabilidade Fiscal (LRF). Receita Corrente Líquida (RCL). Transparência.

\section{INTRODUÇÃO}

Despesas com pessoal é considerado um dos assuntos, dentre os mais discutidos nas despesas públicas em qualquer âmbito das esferas governamentais. A transparência fiscal muito embora seja de caráter obrigatório, passa a ser revelada aos cidadãos mediante as publicações dos dados através dos Relatórios de Gestão Fiscal, para serem analisados requerem mínimo conhecimento técnico e prévio (FARIAS, 2009).

A Lei de Responsabilidade Fiscal (LRF), de 2000, surgiu com o propósito de estabelecer regras voltadas à transparência dos atos e fatos dos gestores públicos na área de finanças públicas, para o cumprimento correto da gestão fiscal. Mesmo com 12 anos de existência no âmbito da política pública administrativa, é possível notar infrações cometidas em relação ao descumprimento desta lei nas esferas municipais deste país, no que tange principalmente e sendo de extrema relevância as despesas com pessoal no orçamento público (CONGRESSO CONTABILIDADE UFSC, 2009).

1 Acadêmico do curso de Ciências Contábeis da UNEMAT - Campus de Tangará da Serra, e-mail: jandher_j@hotmail.com.

${ }^{2}$ Mestre em Administracion Y Finanzas pela Universidade de Extremadura (2003). Professor do curso de Ciências Contábeis da UNEMAT - Campus de Tangará da Serra, e-mail: magnoalves@ unemat.br. 
Destaca-se entre os principais objetivos desta lei a eliminação dos déficits crônicos da administração pública, com os aperfeiçoamentos das técnicas e processos de planejamento, obtendo um melhor controle do endividamento e mais austeridade na execução dos orçamentos (CLEMENTE; GERIGK; TAFFAREL, 2010).

Os limites para despesas com pessoal não surgiram com a LRF, na Constituição Federal (CF) de 1967 em seu art. 66 já retratava o assunto, assim como a Lei Rita Camata em suas versões de 1995 e 1998 que tiveram o propósito de disciplinar esses gastos em conjuntura à CF de 1988. Mas foi com o advento da LRF e suas sanções rigidamente estabelecidas aos infratores, que foi modificado toda estrutura nacional administrativa e em particularidade as fiscalizações oriundas dos Tribunais de Contas estaduais e federal (CONGRESSO CONTABILIDADE UFSC, 2009).

Nesta perspectiva, procura-se identificar o comprometimento da Receita Corrente Líquida (RCL) diante das despesas com pessoal, baseando-se nos estudos do município de Videira-SC apontados no artigo do Congresso Contabilidade UFSC (2009), e nos estudos de Clemente, Gerigk, Taffarel (2010) nos municípios brasileiros de médio porte, bem como observar a evolução destes gastos. Propõe-se, portanto como questão problema para esta pesquisa: Qual a situação das despesas com pessoal dos municípios de Denise e Tangará da Serra - MT, referente aos anos 2007 a 2010, em relação aos limites impostos pela Lei de Responsabilidade Fiscal?

Diante desse problema, surgiram as seguintes hipóteses: H1 - Os gastos com pessoal auferidos nos municípios de Denise e Tangará da Serra - MT estiveram na média de gastos da região; H2 - Durante o período pesquisado ambos os municípios apresentaram abaixo do limite prudencial da LRF.

Tomando como base a pesquisa de Zulian (2010) no município de Cachoeirinha - RS, que buscou comparar os limites impostos às despesas com pessoal em relação ao seu cumprimento, analisando os relatórios emitidos pela administração pública, este artigo também tem como objetivo geral: analisar as despesas com o pessoal nos municípios de Denise e Tangará da Serra - MT nos anos de 2007 a 2010; e que se estende através dos seguintes objetivos específicos: identificar o comprometimento da Receita Corrente Líquida com relação aos gastos com pessoal, verificar a situação destes gastos em relação à LRF e comparar com a média da Região VIII do (ZSEE) - MT.

Busca-se através deste estudo e diante da análise do contexto, oferecer aos munícipes uma visão panorâmica e aos gestores públicos um modelo comparativo das despesas com 
pessoal, diante dos limites apresentados pela (LRF). Em relação aos dados analisados, não se destina a julgamento ético ou moral, no entanto, serão expostos de maneira sintetizada para facilitar a visualização dos gastos, por terem destaque expressivo e influenciar diretamente na reputação de qualidade da gestão pública.

De certa forma, o intuito e as contribuições que esta pesquisa pode proporcionar além do incentivo ao acompanhamento dos gastos públicos é também despertar interesse nos acadêmicos em conhecer realmente a situação política administrativa da sociedade na qual estão inseridos, bem como conhecer os dispositivos de controle e fiscalização do dinheiro público, mas os questionamentos sobre a administração pública em descobrir como estão sendo aplicados os recursos financeiros exigirão ainda, maior aprofundamento no assunto.

\section{REFERENCIAL TEÓRICO}

\subsection{Introdução a Lei de Responsabilidade Fiscal}

De acordo com as disposições preliminares do primeiro capítulo, A Lei Complementar n. ${ }^{\circ} 101$ de 4 de maio de 2000 (Lei de Responsabilidade Fiscal), amparada pelo capítulo II do título VI da constituição, estabelece um planejamento transparente para que se possa alcançar o equilíbrio das contas públicas previnindo-se de erros e desvios, mediante a conciliação de receitas e despesas estabelecidas em metas fiscais orçamentárias.

A Lei de Responsabilidade Fiscal está apoiada em quatro eixos: o planejamento, a transparência, o controle e a responsabilização, que, em seu conjunto, são orientadores para a implantação do modelo de informações gerenciais, pois o planejamento e o controle são instrumentos fundamentais para a geração de informações úteis para auxiliar o processo decisório e consequentemente melhorar os demais eixos: a transparência e a responsabilização (SILVA, 2004 apud CLEMENTE; GERIGK; TAFFAREL, 2010).

Pode-se afirmar ser de suma importância o papel da contabilidade diante a administração pública, no cumprimento da Lei de Responsabilidade Fiscal (LRF), quanto à prestação de contas, ao órgão auxiliar de fiscalização externa (Tribunal de Contas dos Municípios ou Tribunal de Contas dos Estados) para emissão de parecer sobre a Gestão Fiscal (SLOMSKI, 2003).

Diante do estabelecido no art. $1^{\circ}$ da LRF, um de seus ditames é controlar e regulamentar os limites dos gastos com pessoal, para contribuir e sustentar-se aos seus 
princípios. Porém esta não é a primeira lei a tratar sobre despesas com pessoal, a lei Rita Camata em suas versões I e II, também já trataram sobre o assunto.

\subsection{Administração Pública}

A Constituição Federal regulamenta em seu art. 37, que a administração pública direta e indireta de qualquer dos poderes das esferas administrativas deverá obedecer aos princípios de legalidade, impessoalidade, moralidade, publicidade e eficiência.

Nessa concepção Moraes (2007), defini-se objetivamente como atividade a ser desenvolvida pelo Estado de forma imediata com o propósito de desenvolver os interesses coletivos e subjetivamente como conglomerado de órgãos e de pessoas jurídicas aos quais são conferidos o exercício de função administrativa do Estado.

Para Silva (2007, p.655) o conceito de administração pública resume-se em

o conjunto de meios institucionais, materiais, financeiros e humanos preordenados à execução das decisões políticas. Essa é uma noção simples de Administração Pública que destaca, em primeiro lugar, que é subordinada ao Poder Público, em segundo lugar, que é meio e, portanto, algo de que se serve para atingir fins definidos e, em terceiro lugar, denota os seus dois aspectos: um conjunto de órgãos a serviço do Poder político e as operações, as atividades administrativas.

\subsection{Orçamento Público}

O sistema orçamentário encontra-se fundamentado constitucionalmente nos arts. 165 a 169, dentre as várias definições de orçamento público pode-se destacar para compreensão as seguintes definições. Conforme Baleeiro (2001, p. 411 apud BEZERRA FILHO, 2005, p.83)

\footnotetext{
Ato pelo qual o Poder Legislativo autoriza, ao Poder Executivo, por certo período e em pormenor, as despesas destinadas ao funcionamento dos serviços públicos e outros fins adotados pela política econômica ou geral do país, assim como a arrecadação das receitas já criadas em lei.
}

Em outra concepção, o orçamento pode ser enxergado objetivamente ou subjetivamente. No aspecto objetivo quando aponta a área das Ciências das Finanças que estuda o conjunto de normas e a Lei do Orçamento no que se refere a sua preparação, sanção legislativa, execução e controle, ou seja, fase preventiva, executiva e crítica de todas as etapas do orçamento. No aspecto subjetivo, ao colocar os representantes legitimamente eleitos, diante dos gastos do exercício que deverão ser aprovados (SILVA, 2004).

Conceitua-se como uma ferramenta de governo de extrema complexibilidade, porque pode ser definido como processo e o conjunto de documentos integrados pelos quais se preparam, se expressam, se aprovam, se realizam e se apreciam os planos e programas de obras, serviços e encargos, com estimação da receita e fixação das despesas de cada período 
financeiro, e sempre apresentada em forma de partidas dobradas em cumprimento ao seu aspecto contábil (SILVA, 2007).

No entanto vale resaltar que orçamento público não é somente uma contabilidade de previsão de receitas e fixação de despesas, abrange grande número de pessoas, expressando as políticas desenvolvidas pela entidade pública, interesses que nele predominam e os setores beneficiados (ANDRADE, 2002).

Estabelecidos e regulamentados pela Lei Federal $n^{\circ} 4.320 / 64$ e Lei Complementar $n^{\circ}$ 101/00, obedecendo os mandamentos da Constituição Federal de 1988, que estabeleceu instrumentos de planejamento governamental, os projetos deverão obedecer uma ordem cronológica sendo, Projeto de Lei do Plano Plurianual, Projeto de Lei de Diretrizes Orçamentárias e Projeto de Lei Orçamentária Anual.

O orçamento público pode ser entendido como uma técnica especializada em administrar e organizar a melhor aplicação dos recursos financeiros disponiveis, através de ciclo orçamentário que compreende: Elaboração, Estudo e aprovação, Execução e Avaliação.

Um dos fatores fundamentais e de suma importância, é a contabilidade no ciclo orçamentário, devido a contribuição na condução do negócios e controles públicos, satisfazendo não somente os requisitos da própria contabilização, sendo “ a principal fonte informativa dos instrumentos da chamada Transparência da Gestão Fiscal. [...], aos quais será dada ampla divulgação, inclusive em meios eletrônicos de acesso público [...]"(KOHAMA, 2003, p. 71).

\subsection{Receitas Corrente Líquida (RCL)}

Em sua classificação econômica as receitas orçamentárias são compostas pelas Receitas Corrente, fatos modificativos aumentativos, também denominado primária ou efetiva, destinadas a manutenção administrativa e custeio, ou seja, para atender as despesas correntes (CASTRO; LIMA, 2003). Machado Jr., Reis (1975 apud KOHAMA, 2006, p. 64) expõe como conceito de operações correntes, "as que não provenham da alienação de um bem de capital, não estejam, na lei, definidas como de capital e estejam por ato do poder público vinculados a uma despesa corrente (transferência corrente)”.

A definição estabelecida pela lei a quem compete pode ser compreendida como:

São Receitas Correntes as receitas tributárias de contribuições, patrimonial, agropecuária, industrial, de serviços e outras e, ainda, as provenientes de recursos financeiros recebidos de outras pessoas de direito público ou privado, quando 
destinadas a atender despesas classificáveis em Despesas Correntes $\left(\S 1^{\circ}\right.$ do

Artigo11, da Lei Federal no 4.320/64).

Uma variável de grande relevância para o estudo de apuração das despesas com pessoal é a Receita Corrente Líquida (RCL), que representa para LRF uma expressão que define uma série de limites fiscais, de despesas com pessoal, operações de crédito e dívida consolidada (CONGRESSO CONTABILIDADE UFSC, 2009). Definida pela LRF no inciso IV do art. $2^{\circ}$ como sendo a soma das receitas tributárias, de contribuições, patrimoniais, industriais, agropecuárias, de serviços, tranferências correntes e outras receitas correntes, deduzidas as contribuições mencionadas no art. 195 e art. 239 da Constituição Federal, as parcelas entregues aos municípios, e as contribuições dos servidores para o custeio do sistema previdenciário e assistência social.

\subsection{Despesas Públicas e suas classificações}

Entende-se como despesa orçamentária as que estejam discriminadas e fixadas no orçamento e cuja realização depende de autorização legislativa, através de normas legais, não podendo realizar-se sem crédito orçamentário correpondente (ANDRADE, 2002).

As despesas públicas podem ser conceituadas como

Todo pagamento efetuado a qualquer título pelos agentes pagadores para saldar gastos fixados na lei do orçamento ou em lei especial e destinados à execução dos serviços públicos, entre eles custeios e investimentos, além dos aumentos patrimoniais, pagamentos de dívidas, devolução de importâncias recebidas a títulos de caução, depósitos e consignações (ANDRADE, 2002, p. 75).

As despesas públicas orçamentárias, também são compostas por: Despesas correntes, realizadas pela administração pública, define-se como gastos de natureza operacional, a fim de executar a manutenção dos equipamentos e promover o funcionamento dos orgãos e de suas atividades básicas, apresenta-se como fato modificativo ou diminutivo, mas não contribui diretamente para a formação ou aquisição de um bem de capital, mas que necessitam maior dispêndio de recursos públicos para saldá-las (KOHAMA, 2003).

Quanto a sua classificação econômica Clemente, Gerigk e Taffarel (2010) definem basicamente, as despesas corrente como as que são destinadas à manutenção da entidade, como: materias e insumos, pagamento de pessoal e encargos socais entre outras; enquanto as depesas de capital são destinadas a aquisições de bens de capital, aumentando o patrimônio da entidade. 
É através dos ditames legais que a legislação vem cada vez mais exigindo o cumprimento de percentuais mínimos e máximos para o atendimento das necessidades da população em geral, afim de fazer com que cumpram o papel correto do Estado, que é promover benefícios públicos mediante a atos e fatos administrativos. Esses limites constitucionais e legais, que obrigam o município a destinar parte de sua receita a determinado fim, estabelecendo certos parâmetros para a limitação também de certas despesas (ANDRADE, 2002).

\subsubsection{Despesas com pessoal}

A Lei Complementar 101 de 2000, estabelece e deixa claro em seu art. 18 o principal conceito de despesa total com pessoal sendo;

Art. 18. Para os efeitos desta Lei Complementar, entende-se como despesa total com pessoal: o somatório dos gastos do ente da Federação com os ativos, os inativos e os pensionistas, relativos a mandatos eletivos, cargos, funções ou empregos, civis, militares e de membros de Poder, com quaisquer espécies remuneratórias, tais como vencimentos e vantagens, fixas e variáveis, subsídios, proventos da aposentadoria, reformas e pensões, inclusive adicionais, gratificações, horas extras e vantagens pessoais de qualquer natureza, bem como encargos sociais e contribuições recolhidas pelo ente às entidades de previdência.

$\S 1$ o Os valores dos contratos de terceirização de mão-de-obra que se referem à substituição de servidores e empregados públicos serão contabilizados como "Outras Despesas de Pessoal".

$\S 20$ A despesa total com pessoal será apurada somando-se a realizada no mês em referência com as dos onze imediatamente anteriores, adotando-se o regime de competência.

A ação projetada e transparente, proposta pela LRF, contribui para a responsabilidade na gestão fiscal, resguardando o equilíbrio das contas públicas, ao se corresponder às metas, às condições e os limites estipulados. Impondo um regime de gestão responsável, além de pautar os limites das despesas com pessoal (ZULIAN, 2010).

Helena (2006) entende que, a boa administração para as finanças públicas perdeu seu caráter absoluto, tendo sido abandonado pela doutrina do equilíbrio geral e formal, mesmo não deixando de requerer um equilíbrio dinâmico. Inserem-se neste contexto as normas que limitam os gastos com o pessoal, agora sob as normas da Constituição Federal de 1988, art. 169, ou a vedação à assunção de obrigações superiores às dotações orçamentárias.

Complementa ainda com relação a Lei de Responsabilidade Fiscal, em ser o princípio do equilíbrio fiscal. Esse princípio, significa que o Estado deverá pautar sua gestão pelo equilíbrio orçamentário, entre receitas e despesas. Dessa forma, toda vez que ações ou fatos 
venham a desviar a gestão da equalização, deverão ser tomadas medidas para que o equilíbrio retome à trajetória (HELENA, 2006).

\subsubsection{Limites das despesas com pessoal}

Dias (2009) acredita que uma razão para esses limites é que o descontrole de gastos com despesas com pessoal pode ter consequências desastrosas à administração pública, considerando ser este, um dos principais itens de despesa do setor público no Brasil. Um ente público compromete a maior parte de sua receita disponível com pessoal, como não era incomum com estados e municípios na década de 80, implica no empenho das políticas públicas, devido a insuficiência de recursos para os programas de governo.

Em caso do valor da despesa total com pessoal em qualquer Poder ou orgão das esferas ultrapassar os limites definidos, o percentual correspondente ao excedente deverá ser eliminado nos próximos dois quadrimestres, sendo pelo menos um terço no primeiro (LRF, Art. 23).

De acordo com o art. 19 da LRF, a Despesa Total com o Pessoal (DTP), em cada período de apuração e em cada ente da Federação, não poderá exceder os percentuais da receita corrente liquida, a seguir discriminados:

I - União: $50 \%$ (cinqüenta por cento);

II - Estados: 60\% (sessenta por cento);

III - Municípios: 60\% (sessenta por cento).

Os limites distribuídos entre os poderes e órgãos são definidos na mesma lei no art. 20 que define a repartição dos limites globais do art. 19 não poderá exceder os seguintes percentuais:

III - na esfera municipal;

a) 6\% (seis por cento) para o Legislativo, incluído o Tribunal de Contas do Município, quando houver;

b) $54 \%$ (cinqüenta e quatro por cento) para o Executivo.

No que tange ao Poder Executivo, em qualquer das repartições de governo, no que se refere às despesas com pessoal, deverão ser incluídas inclusive os gastos com a administração indireta, bem como o somatório também das despesas pertencentes a administração direta, fundos, fundações, autarquias e empresas estatais dependentes (CRUZ, 2002 apud SANTOS; LUCHI, 2005).

A Lei de Responsabilidade Fiscal retrata em seu art. 22 as vedações e o momento que deverá ter atenção especial em relação aos gastos com pessoal, ao atingir o limite de 95\% 
(noventa e cinco por cento) denominado limite prudencial, vedando ao Poder ou orgão referido no art. 20 que houver incorrido no excesso:

I - concessão de vantagem, aumento, reajuste ou adequação de remuneração a qualquer título, salvo os derivados de sentença judicial ou de determinação legal ou contratual, ressalvada a revisão prevista no inciso X do art. 37 da Constituição;

II - criação de cargo, emprego ou função;

III - alteração de estrutura de carreira que implique aumento de despesa;

IV - provimento de cargo público, admissão ou contratação de pessoal a qualquer título, ressalvada a reposição decorrente de aposentadoria ou falecimento de servidores das áreas de educação, saúde e segurança;

$\mathrm{V}$ - contratação de hora extra, salvo no caso do disposto no inciso II do § 6o do art. 57 da Constituição e as situações previstas na lei de diretrizes orçamentárias.

Embora a lei não utilize este termo "limite prudencial", as penalidades administrativas relacionadas a gestão de pessoal são rigorosas, em todos os aspectos relacionados à remuneração, alteração de carreiras e contratação (CONGRESSO CONTABILIDADE UFSC, 2009).

\subsection{Punições e sanções}

A sistemática de punição para os maus gestores vem sendo colocada em prática desde a promulgação da CF de 88, mas sem muito sucesso. A LRF de 2000 estabeleceu os limites de gastos a serem cumpridos, cabendo aos Tribunais de Contas, além de verificar o cumprimento desses limites, alertar ao ultrapassarem 90\% dos limites aplicáveis e quando as despesas com inativos e pensionistas encontrarem-se acima do limite correspondente (NASCIMENTO, 2008).

De acordo com a LRF (2000), em seu art. 22 a despesa total com pessoal que exceder a 95\% do limite, são vedados ao Poder ou orgão [...];

\footnotetext{
I - concessão de vantagem, aumento, reajuste ou adequação de remuneração a qualquer título, salvo os derivados de sentença judicial ou de determinação legal ou contratual, ressalvada a revisão prevista no inciso $\mathrm{X}$ do art. 37 da Constituição;

II - criação de cargo, emprego ou função;

III - alteração de estrutura de carreira que implique aumento de despesa;

IV - provimento de cargo público, admissão ou contratação de pessoal a qualquer título, ressalvada a reposição decorrente de aposentadoria ou falecimento de servidores das áreas de educação, saúde e segurança;

$\mathrm{V}$ - contratação de hora extra, salvo no caso do disposto no inciso II do $\S 6^{\circ}$ do art. 57 da Constituição e as situações previstas na lei de diretrizes orçamentárias.
}

Nesse mesmo sentido, e conforme o art. 23 da referida lei, se a despesa com pessoal ultrapassar os limites definidos, sem prejuízo das medidas previstas no art. 22, o percentual excedente terá de ser eliminado nos dois quadrimestres seguinte, sendo um terço no primeiro. 
Despesas públicas: análise das despesas com pessoal nos municípios da região VIII do Zoneamento Sócio Econômico Ecológico - MT

Jandher Jonnathan de Araújo, Me. Magno Alves Ribeiro

Com o advento da Lei 10.028 de 19 de outubro de 2000 conhecida como Lei de Crimes Fiscais, que qualifica como crimes o decumprimento de algumas regras da LRF, bem como em seu art. $5^{\circ}$, IV, revela perda de mandato, reclusão de 1 a 4 anos e pagamento de multa de $30 \%$ dos vencimentos anuais.

\section{Quadro 1. Infrações da Lei de Responsabilidade Fiscal e suas penalidades}

\begin{tabular}{|c|c|}
\hline Infração & Sanção/Penalidade \\
\hline $\begin{array}{l}\text { Deixar de apresentar e publicar o Relatório de } \\
\text { Gestão Fiscal, no prazo e com o detalhamento } \\
\text { previsto na lei (LRF, artigos } 54 \text { e 55; Lei no } \\
10.028 / 2000 \text {, art. 50, inciso I). }\end{array}$ & $\begin{array}{l}\text { Multa de } 30 \% \text { dos vencimentos anuais (Lei no } \\
10.028 / 2000 \text {, art. } 50 \text {, inciso I e } \S 1^{\circ} \text { ). Proibição } \\
\text { de receber transferências voluntárias e contratar } \\
\text { operações de crédito, exceto as destinadas ao } \\
\text { refinanciamento do principal atualizado da dívida } \\
\text { mobiliária (LRF, art. } 51, \S 2^{\circ} \text { ). }\end{array}$ \\
\hline $\begin{array}{l}\text { Ultrapassar o limite de Despesa Total com } \\
\text { Pessoal em cada período de apuração (LRF, art } \\
19 \text { e 20). }\end{array}$ & $\begin{array}{l}\text { Cassação do mandato (Decreto-Lei no 201, art. } \\
40 \text {, inciso VII). }\end{array}$ \\
\hline $\begin{array}{l}\text { Expedir ato que provoque aumento da Despesa } \\
\text { com Pessoal em desacordo com a lei (LRF, art. } \\
21 \text { ). }\end{array}$ & $\begin{array}{l}\text { Nulidade do ato (LRF, art. 21); Reclusão de um a } \\
\text { quatro anos (Lei no } 10.028 / 2000 \text {, art. } 2^{\circ} \text { ) }\end{array}$ \\
\hline $\begin{array}{l}\text { Expedir ato que provoque aumento da Despesa } \\
\text { com Pessoal nos cento e oitenta dias anteriores } \\
\text { ao final do mandato do titular do respectivo } \\
\text { Poder ou órgão (LRF, art. } 21 \text { ). }\end{array}$ & $\begin{array}{l}\text { Nulidade do ato (LRF, art. } 21 \text {, } \S \text { único); Reclusão } \\
\text { de um a quatro anos (Lei no } 10.028 / 2000 \text {, art. } \\
2^{\circ} \text { ) }\end{array}$ \\
\hline $\begin{array}{l}\text { Deixar de adotar as medidas previstas na LRF, } \\
\text { quando a Despesa Total com Pessoal do } \\
\text { respectivo Poder ou órgão exceder a } 95 \% \text { do } \\
\text { limite (LRF, art. 22). }\end{array}$ & $\begin{array}{l}\text { Reclusão de um a quatro anos (Lei no } \\
10.028 / 2000, \text { art. 20).Proibições previstas em lei } \\
\text { (LRF, art. 22, § único). }\end{array}$ \\
\hline $\begin{array}{l}\text { Deixar de adotar as medidas previstas na lei, } \\
\text { quando a Despesa Total com Pessoal } \\
\text { ultrapassar o limite máximo do respectivo } \\
\text { Poder ou órgão (LRF, art. 23). }\end{array}$ & $\begin{array}{l}\text { Reclusão de um a quatro anos (Lei no } \\
10.028 / 2000 \text {, art. 20). }\end{array}$ \\
\hline $\begin{array}{l}\text { Manter gastos com inativos e pensionistas } \\
\text { acima do limite definido em lei (LRF, artigos } 18 \\
\text { a } 20 \text {, art. } 24 \S 20 \text {, art. } 59, \S 10 \text {, inciso IV). }\end{array}$ & $\begin{array}{l}\text { Cassação do mandato (Decreto-Lei no 201, art. } \\
4^{\circ} \text {, inciso VII). }\end{array}$ \\
\hline $\begin{array}{l}\text { Não cumprir limite de Despesa Total com } \\
\text { Pessoal em até dois anos, caso o Poder ou } \\
\text { órgão tenha estado acima desse limite em } 1999 \\
\text { (LRF, art. } 70) \text {. }\end{array}$ & $\begin{array}{l}\text { Proibição de receber transferências voluntárias, } \\
\text { contratar operações de crédito e de obter } \\
\text { garantias (LRF, art. 23, } \S 3^{\circ} \text { ). Cassação do } \\
\text { mandato (Decreto-Lei no } 201 \text {, art. } 4^{\circ} \text {, inciso } \\
\text { VII). }\end{array}$ \\
\hline $\begin{array}{l}\text { Não cumprir, até } 2003 \text {, o limite de Despesa } \\
\text { Total com Pessoal do exercício em referência } \\
\text { que não poderá ser superior, em percentual da } \\
\text { Receita Corrente Líquida, a despesa verificada } \\
\text { no exercício imediatamente anterior, acrescida } \\
\text { de até dez por cento, se esta for inferior ao } \\
\text { limite definido em lei (LRF, art. 71). }\end{array}$ & $\begin{array}{l}\text { Cassação do mandato (Decreto-Lei no 201, art. } \\
4^{\circ} \text {, inciso VII). }\end{array}$ \\
\hline
\end{tabular}

Fonte: Adaptado Tesouro Nacional (2012).

\subsection{Relatório Resumido da Execução Orçamentária (RREO) e Relatório de Gestão Fiscal (RGF)}

Dois novos demonstrativos contábeis foram inseridos como obrigatoriedade para todos os entes públicos com o surgimento da LRF, o Relatório Resumido da Execução 
Orçamentária (RREO) e o Relatório de Gestão Fiscal (RGF). Para estabelecer a padronização dos demonstrativos fiscais em todas as esferas de governo também foi criado o Manual Técnico de Demonstrativos Fiscais, tendo o propósito de garantir a consolidação das contas públicas conforme determinado pela LRF, expresso na 1a edição Portaria STN nº 577/2008.

O RREO é exigido e obrigatoriamente deve ser publicado até trinda dias após o encerramento de cada bimestre ${ }^{3}$, e objetiva-se em permitir, que cada vez mais, a sociedade, analise o andamento e desempenho da execução orçamentária e conheça o controle através dos diversos orgãos que deverão obedecer esta condição pré estabelecida (MANUAL DE DEMONSTRATIVOS FISCAIS, 2010).

Na concepção de Cruz et al (2006, apud FARIAS, 2009) os dados dispostos no RREO facilita a análise confrontante entre o que foi orçado e o que foi executado e o progresso do orçamento corrente, em que os resultados de déficit ou superávit orçamentário fica explicitamente evidenciado.

No que tange ao Relatório de Gestão Fiscal, após o término de cada quadrimestre este relatorio deverá ser desenvolvido devidamente assinado pelos responsáveis da administração financeira e pelo controle interno do ente público, e em até trinta dias deverá ser publicado, reelado em audiência pública, com amplo acesso e inclusive em meios eletrônico (art. 54 e 55, LRF).

Os entes que estiverem obrigados à publicação do RREO e RGF, e eventualmente não respeitarem o prazo estabelecido pela LRF poderão ficar impedidos de obter transferências voluntárias e contratar operações de crédito, com excessão daquelas que são destinadas ao refinanciamento do principal corrigido da dívida mobiliária (PLATT NETO, 2009 apud FARIAS, 2009). Vale resaltar ainda, que os relatórios citados são regulamentados e elaborados conforme os moldes da Secretaria do Tesouro Nacional (STN), do Ministéiro da Fazenda (FARIAS, 2009).

A divulgação do RGF conforme o art. 63 da LRF “é facultado aos Municípios com população inferior a cinquenta mil habitantes", no entanto deverá ser realizada até trinta dias após o encerramento do semestre. Se ultrapassados os limites relativos a despesa com pessoal ou à dívida consolidada, deverá este ente publicar e obedecer os mesmos prazos que os demais, por enquanto perdurar essa irregularidade de situação.

${ }^{3} \mathrm{CF}$, art. $165, \S 3^{\circ}$. 


\section{METODOLOGIA}

A metodologia aplicada é de natureza descritiva, pois, expõe o comportamento das despesas com pessoal através dos fatos observados, registrados, analisados, classificados e interpretados, sem que o pesquisador manipule-os (ANDRADE, 2010, p. 112).

A área delimitada para estudo foi a região VIII das 12 definidas pelo Zoneamento Sócio Econômico Ecológico de Mato Grosso (ZSEE) pertencente à Secretaria de Estado de Planejamento e Coordenação Geral, que buscou dotar o Governo de bases técnicas para espacialização de políticas públicas, dividindo os 141 municípios do estado (ZONEAMENTO, 2012).

Os dados foram analisados nos sites das prefeituras em estudo, diário oficial dos municípios de Mato Grosso, do Sistema de Coleta de Dados Contábeis de Estados e Municípios (SISTN), Relatórios e Anexos publicados periodicamente, e extraídos a partir dos pareceres e relatórios do Tribunal de Contas do Estado de Mato Grosso.

As despesas com pessoal analisadas foram as provenientes de gastos do Poder Executivo de cada município. Com as informações desses dados, foram constituídas tabelas baseadas nos modelos apresentados no artigo Congresso Contabilidade UFSC (2009), a fim de analisar o comprometimento da RCL, os gastos com pessoal com relação aos limites estabelecidos pela LRF e comparar em média os percentuais do município de Denise e Tangará da Serra - MT com os da Região VIII do (ZSEE), que é composta por 8 municípios, tendo como cidade pólo Tangará da Serra e os demais municípios, Porto Estrela, Barra do Bugres, Nova Olímpia, Denise, Santo Afonso, Campo Novo dos Parecis e Brasnorte que compõem o grupo. Os períodos trabalhados são os anos de 2007 a 2010, respectivamente correspondentes a anterior e atual gestão administrativa.

As principais dificuldades durante a execução da pesquisa foram encontrar divergências nos dados publicados, os RGF se apresentaram com valores diferentes nas fontes pesquisadas em alguns períodos, e isso dificultou a análise no princípio. Antes da tabulação, foram feitas comparações dos valores entre as fontes de maior credibilidade, TCE-MT, SISTN e Diário Oficial dos Municípios Matogrossense, no entanto, foi utilizada uma única fonte, sendo o TCE-MT, pois se subentende que as contas aqui tratadas já tenham sido supervisionadas e auditadas por este órgão competente. 
Os cálculos das tabelas, também mencionado nos trabalhos de (CLEMENTE; GERIGK; TAFFAREL, 2010) que serviram de base contém as seguintes fórmulas; no Quadro 2 que demonstra as variáveis da tabela 1, e no Quadro 3 as variáveis da tabela 2.

Quadro 2. Demonstrativo de Cálculo.

\begin{tabular}{|cl|l|}
\hline \multicolumn{2}{|c|}{ Variável } & \multicolumn{1}{|c|}{ Indicação } \\
\hline Despesa Total com Pessoal & $=$ & $\begin{array}{l}\% \text { da RCL (Coeficiente de gastos com pessoal } \\
\text { em relação à receita corrente líquida) }\end{array}$ \\
\hline RCL & $=$ & Limite Máximo. \\
\hline Limite Máximo *95\% & $=$ & Limite Prudencial. \\
\hline Limite Máximo $* 90 \%$ & $=$ & Limite Alerta. \\
\hline
\end{tabular}

Fonte: Autor (2012)

Quadro 3. Demonstrativo de Cálculo.

\begin{tabular}{|c|c|c|}
\hline Variável & & Indicação \\
\hline $\begin{array}{c}\text { Despesa Total com Pessoal } \\
\text { No Habitantes }\end{array}$ & $=$ & Valor gasto com pessoal por habitante. \\
\hline$\frac{\mathrm{RCL}}{\text { No Habitantes }}$ & $=$ & Valor da RCL por habitante. \\
\hline
\end{tabular}

Fonte: Autor (2012)

O gráfico 1 foi utilizado de forma simplificada, para demonstrar a evolução das despesas com pessoal apontadas na tabela 1 .

O número de habitantes utilizado na pesquisa no qual foram apresentados nas Tabelas, são informações obtidas do Instituto Brasileiro de Geografia e Estatística (IBGE), pela Contagem População em 2007 e Censo 2010.

Quanto aos procedimentos a metodologia aplicada é a bibliográfica e documental, que se diferenciam basicamente nos documentos utilizados como fonte. Para Andrade (2010) livros e outros documentos bibliográficos, fontes secundárias, são considerados pesquisa bibliográfica, já a pesquisa documental origina-se da extração de documentos de fontes primárias, textos originais, chamados "de primeira mão".

Prestes (2005) define pesquisa bibliográfica a que tenta resolver um problema ou adquirir conhecimentos através da extração de informações de temas e trabalhos já abordados por outros estudiosos perscrutando aspectos publicados em bibliotecas, editoras, videotecas, na internet, entre outras fontes. 
A abordagem do problema é caracterizada como pesquisa quantitativa e qualitativa, através dos dados coletados dos demonstrativos contábeis e dados numéricos. Salienta Beuren (2006, p.92 apud FARIAS, 2009) "na pesquisa qualitativa concebem-se análises mais profundas em relação ao fenômeno que está sendo estudado", quanto à abordagem quantitativa complementa "[...] é freqüentemente aplicada nos estudos descritivos, que procuram descobrir e classificar a relação entre variáveis e a relação de causalidade entre fenômenos". Portanto, a diferença principal entre esses dois métodos é que enquanto qualitativo busca expor aquilo que se diz do sujeito, o quantitativo evidencia o objeto pesquisado.

\section{RESULTADOS}

Para obtenção, coleta e tratamento dos dados foram utilizados os Relatórios provenientes de pareceres técnicos emitidos pelo TCE-MT, sendo assim os índices foram calculados individualmente para cada município da região definida em estudo, e a partir desta coleta anual, obtendo em síntese os valores e limites de gastos com pessoal baseado na Receita Corrente Líquida. No entanto, da região também foi apresentada a média aritmética simples do percentual comprometido das RCL em relação às despesas incorridas em cada período.

Como parâmetros de análise também foram utilizados os valores gastos com Despesa Total de Pessoal por Habitante e a RCL por Habitante, e as médias aritméticas simples respectivamente. A Tabela 1 apresenta os dados e apurações relativos à despesa total com pessoal do poder executivo. O Gráfico 1 apresenta a evolução das despesas com pessoal entre os anos de 2007 e 2010. Na Tabela 2 consta os dados relativos à despesa total com pessoal e receita corrente líquida do poder executivo, por habitante.

Com base na Tabela 1, algumas considerações podem ser feitas sobre os municípios enfatizados. Tangará da Serra se apresentou no ano de 2007 e 2008 como o $4^{\circ}$ município que mais compromete a RCL. Neste primeiro ano com 43,78\% sendo 1,11 pontos percentuais acima da média da região, enquanto em 2008 com 44,27\% sendo 1,43 pontos percentuais acima da média. Denise apresentou o $2^{\circ}$ menor índice de comprometimento em 2007 com $39,11 \%$ da RCL, estando 3,56 pontos percentuais abaixo da média de gastos, em 2008 foi o município que menos gastou comprometendo apenas 31,60\% de sua RCL, 11,24 pontos percentuais abaixo da média da região. 
Durante os dois primeiros períodos, com exceção de Brasnorte com 52,86\% em 2007 e Campo Novo dos Parecis com 53,84\% em 2008, que estiveram acima do Limite Prudencial $51,30 \%$ da RCL (95\% do Limite Máximo), todos os municípios obedeceram aos limites da LRF, estiveram abaixo do limite alerta que é 48,60\% da RCL (90\% do Limite Máximo).

Em comparação à pesquisa do Congresso Contabilidade UFSC (2009) no município de Videira-SC, que no ano 2007 apresentou 45,90\% de gastos da RCL e 45,55\% em 2008, percebe-se que Denise e Tangará da Serra tiveram comprometimento menor de suas RCL em ambos os períodos. Contudo, em comparação à pesquisa de Clemente, Gerigk e Taffarel (2010), com os municípios de médio porte assim definidos por eles, com população entre 100 mil e 1 milhão de habitantes, a média de gastos no ano de 2007 foi de 43,20\%, superior a média de gastos da Região VIII deste artigo que apresentou neste mesmo período 42,67\%, e no ano de 2008 apresentou 42,84\% que por vez foi superior a média dos municípios de médio porte que revelaram ser de $41,30 \%$.

Tabela 4. Comparativo dos Gastos com Pessoal - Poder Executivo, 2007 a 2010. Região VIII - ZSEE. 
Despesas públicas: análise das despesas com pessoal nos municípios da região VIII do Zoneamento Sócio Econômico Ecológico - MT

Jandher Jonnathan de Araújo, Me. Magno Alves Ribeiro

\begin{tabular}{|c|c|c|c|c|c|c|}
\hline Ano & \multicolumn{3}{|c|}{2007} & \multicolumn{3}{|c|}{2008} \\
\hline \multirow{2}{*}{ Município } & \multirow{2}{*}{ RCL (R\$) } & \multicolumn{2}{|c|}{ Despesa Total Pessoal } & \multirow{2}{*}{ RCL (R\$) } & \multicolumn{2}{|c|}{ Despesa Total Pessoal } \\
\hline & & $\mathrm{R} \$$ & $\% \mathrm{RCL}$ & & $\mathrm{R} \$$ & $\% \mathrm{RCL}$ \\
\hline Tangará da Serra & 73.984.208,61 & $32.393 .687,60$ & 43,78 & $88.692 .300,84$ & $39.267 .504,40$ & 44,27 \\
\hline Porto Estrela & 6.801 .936 .55 & 2.279 .421 .44 & 33,51 & $7.586 .894,44$ & $2.856 .588,12$ & 37,65 \\
\hline Barra do Bugres & $31.295 .375,78$ & $13.923 .605,70$ & 44,49 & $40.487 .737,39$ & $16.588 .703,37$ & 40,97 \\
\hline Nova Olímpia & $22.696 .676,27$ & $9.242 .560,72$ & 40,72 & $27.857 .695,50$ & $12.960 .681,90$ & 46,52 \\
\hline Denise & $7.780 .921,55$ & $3.042 .754,34$ & 39,11 & $10.892 .108,16$ & $3.442 .234,07$ & 31,60 \\
\hline Santo Afonso & $5.291 .909,21$ & $2.319 .051,66$ & 43,82 & $6.416 .704,79$ & $2.555 .041,58$ & 39,82 \\
\hline Campo N. dos Parecis & $47.841 .518,96$ & $20.600 .855,06$ & 43,06 & $56.586 .527,81$ & $30.463 .897,32$ & 53,84 \\
\hline Brasnorte & $17.357 .457,46$ & $9.175 .840,17$ & 52,86 & $22.172 .952,73$ & $10.660 .067,09$ & 48,08 \\
\hline \multicolumn{3}{|c|}{ Média } & 42,67 & & & 42,84 \\
\hline Ano & \multicolumn{3}{|c|}{2009} & \multicolumn{3}{|c|}{2010} \\
\hline \multirow{2}{*}{ Município } & \multirow{2}{*}{$\mathrm{RCL}(\mathbf{R} \$)$} & \multicolumn{2}{|c|}{ Despesa Total Pessoal } & \multirow{2}{*}{$\operatorname{RCL}(\mathbf{R} \$)$} & \multicolumn{2}{|c|}{ Despesa Total Pessoal } \\
\hline & & $\mathrm{R} \$$ & $\% \mathrm{RCL}$ & & $\mathrm{R} \$$ & $\% \mathrm{RCL}$ \\
\hline Tangará da Serra & $97.809 .002,26$ & $55.576 .036,65$ & 56,82 & $106.386 .999,56$ & $54.154 .283,87$ & 50,90 \\
\hline Porto Estrela & $7.599 .035,48$ & $3.809 .823,57$ & 50,14 & $8.704 .807,25$ & $4.014 .976,39$ & 46,12 \\
\hline Barra do Bugres & $38.399 .801,50$ & $20.176 .782,15$ & 52,54 & $42.260 .607,62$ & $20.407 .647,42$ & 48,29 \\
\hline Nova Olímpia & $28.039 .593,84$ & $14.567 .274,96$ & 51,95 & $30.753 .637,57$ & $15.921 .158,17$ & 51,77 \\
\hline Denise & $11.057 .274,73$ & $4.884 .805,84$ & 44,18 & $11.374 .419,55$ & $5.756 .178,19$ & 50,61 \\
\hline Santo Afonso & $6.315 .504,93$ & $2.632 .714,42$ & 41,69 & $6.876 .449,46$ & $3.139 .099,18$ & 45,65 \\
\hline Campo N. dos Parecis & $52.227 .691,57$ & $26.516 .497,93$ & 50,77 & $58.722 .645,39$ & $29.358 .500,90$ & 50,00 \\
\hline Brasnorte & $24.486 .706,55$ & $11.194 .718,53$ & 45,72 & $27.986 .065,00$ & $14.866 .781,10$ & 53,12 \\
\hline & Média & & 49,23 & & & 49,56 \\
\hline
\end{tabular}

Limite Máximo: 54\% da RCL.

Limite Prudencial: 51,30\% da RCL ou 95\% do Limite Máximo.

Limite Alerta: 48,60\% da RCL ou 90\% do Limite Máximo.

Fonte: Adaptado dos Relatórios (TCE-MT).

Observando em 2009, apenas três municípios tiveram gastos com pessoal abaixo de $50 \%$ da RCL, sendo Denise o segundo que menos gastou neste período, comprometendo somente $44,18 \%$ e 5,05 pontos percentuais abaixo da média. Barra do Bugres esteve acima do Limite Prudencial, entretanto, apenas Tangará da Serra com 56,82\% ultrapassou o Limite Máximo (54\% da RCL) e apresentou 7,59 pontos percentuais acima da média de gastos da região.

Comparando à pesquisa de Zulian (2010) realizada no município de Cachoeirinha-RS e com objetivo semelhante a este artigo, é possível notar que no ano de 2009 apresentou no 
terceiro quadrimestre comprometimento de $47,16 \%$ da Receita Corrente Líquida, diferentemente da maioria dos municípios da região VIII de Mato Grosso, que neste mesmo período estiveram acima do Limite Alerta.

Nota-se que no ano de 2010 cinco municípios ainda comprometem 50\% ou mais de sua RCL, destacando Brasnorte com 53,12\%, que mais gastou com pessoal em proporção à sua receita, e Nova Olímpia com 51,77\%, ambos acima do Limite Prudencial. Tangará da Serra mesmo tendo reduzido sua despesa e aumentado sua receita em relação ao ano anterior, apresentou ter gastos acima do Limite Alerta e acima da média da região 1,34 pontos percentuais. Denise se mostrou com despesas de pessoal 50,61\% da RCL, menor que Tangará da Serra 0,29 pontos e maior do que a média 1,05 pontos percentuais.

Gráfico 1. Evolução do \% das Despesas com Pessoal sobre a RCL de 2007 a 2010.

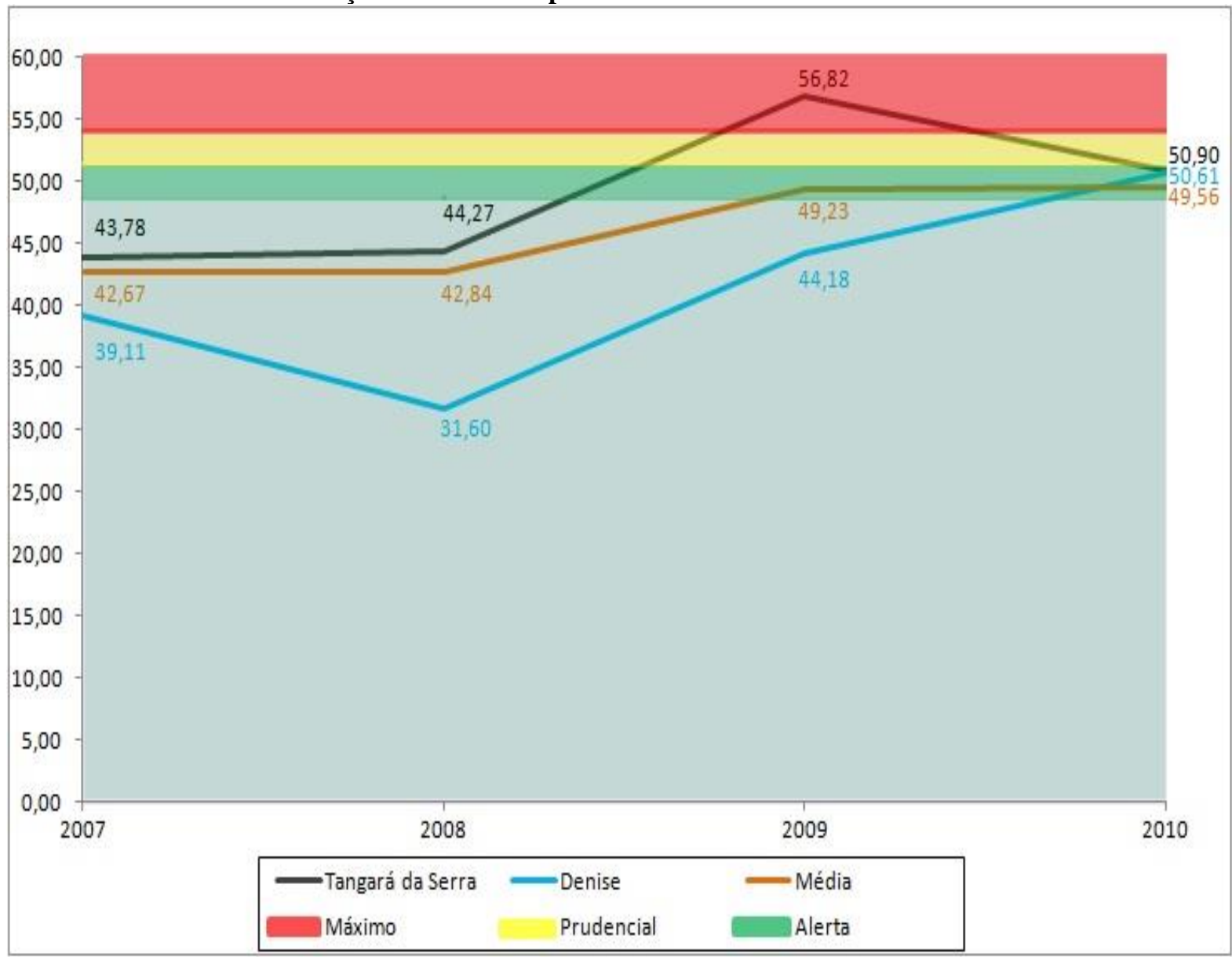

Fonte: Adaptado da Tabela 1 (Autor, 2012).

Os gastos provenientes da folha de pagamento de pessoal em todo setor público brasileiro representa o principal item de despesas. Durante os anos 1996 a 2000, antes da existência da LRF, o conjunto dos Estados brasileiros gastavam em média 67\% (sessenta e 
sete por cento) de suas receitas líquidas com folha de pagamento (DEBUS; NASCIMENTO, 2011).

No Gráfico 1 é possível observar a evolução nas Despesas com Pessoal nestes períodos pesquisados, Tangará da Serra sempre esteve acima da média de toda região VIII, entre 2007 e 2008 esteve abaixo do Limite Alerta, estabelecido pelo Tribunal de Contas do Estado (TCE-MT). No entanto em 2009 teve uma evolução de sua despesa de 41,53\% enquanto sua receita corrente líquida aumentou apenas 10,28\% em relação ao ano anterior, isso proporcionou a um comprometimento da RCL de 56,82\% neste período, o maior dentre os municípios durante o período pesquisado, mas em 2010 devido a evolução em sua RCL de $8,77 \%$ e regressão em suas despesas com pessoal em $2,56 \%$, foram reduzidos 5,92 pontos percentuais.

O município de Denise entre os anos de 2007 e 2009 esteve abaixo da média da região e abaixo do Limite Alerta, seu maior grau de alavancagem ocorreu em 2009 quando sua RCL evoluiu apenas 1,52\% enquanto sua despesa total com pessoal evoluiu 41,91\%. Posteriormente em 2010 esteve acima da média, por ter evoluído com seus gastos 17,84\% e sua receita apenas $2,87 \%$. Muito embora Denise tenha evoluído o seu comprometimento da RCL, durante o período pesquisado nunca esteve acima dos percentuais de gastos de Tangará da Serra.

Com as manifestações grevistas realizadas pelos professores do município de DeniseMT nos anos de 2009 e 2011, foi possível observar a indignação destes profissionais com piso salarial da classe. Houve uma repercussão relativamente intensa sobre o fato, a paralisação perdurou por mais de trinta dias. Pais ficaram revoltados com a situação, e isso fez com que alguns críticos locais se manifestassem sobre a administração do atual prefeito em relação aos gastos com pessoal (TRABALHADORES, 2009).

Os municípios possuem grande responsabilidade, a qual a maior fração compete ao Poder Executivo, para administrar e governar diante das funções políticas que lhes foram atribuídas. Dentre estas, o dever de controlar as receitas e despesas municipais, a fim de oferecer condições básicas de vida e o bem-estar para a população, e acima de tudo, manter o equilíbrio financeiro das contas públicas obedecendo na íntegra às normas da Lei de Responsabilidade Fiscal, evitando punições e sanções da mesma.

Na Tabela 2 é revelado o valor em reais, gasto de Despesa Total com Pessoal (DTP) e o que foi obtido de Receita Corrente Líquida para ser gasto por Habitantes em 2007 e 2010 . A partir daí foi possível observar que o município de Campo Novo dos Parecis é o que mais 
Despesas públicas: análise das despesas com pessoal nos municípios da região VIII do Zoneamento Sócio Econômico Ecológico - MT

Jandher Jonnathan de Araújo, Me. Magno Alves Ribeiro

gastou com DTP na região em 2007, proporcionalmente ao número de habitantes, apresentando em valores R \$ 922,89 e, tinha disponível da RCL R \$ 2.143,25.

Denise com R\$294,01 apresentou em 2007 ser o município que teve menor investimento com pessoal, abaixo da média $\mathrm{R} \$ 278,47$, ou seja, 48,64\%. Consequentemente a RCL exibiu-se como a menor também distribuída pelo número de habitantes, representada por $\mathrm{R} \$ 751,85$ estando 44,21\% abaixo da média que é de $\mathrm{R} \$ 1.347,55$.

Tabela 2. Gastos com Pessoal e Receita Corrente Líquida por Habitante - Poder Executivo, 2007 e 2010. Região VIII - ZSEE.

\begin{tabular}{|c|c|c|c|c|c|}
\hline \multirow{2}{*}{ Ano } & \multirow{2}{*}{ Município } & \multirow{2}{*}{$\frac{\text { Despesa Total Pessoal } *}{\mathbf{N}^{\circ} \text { Habitantes } * * *}$} & \multirow{2}{*}{$\mathbf{R} \$$} & RCL** & \multirow{2}{*}{$\mathbf{R} \$$} \\
\hline & & & & $\mathbf{N}^{\mathbf{0}}$ Habitantes**** & \\
\hline \multirow{8}{*}{2007} & Tangará da Serra & $\frac{32.393 .687,60}{76.657}$ & 422,58 & $\frac{73.984 .208,61}{76.657}$ & 965,13 \\
\hline & Porto Estrela & $\frac{2.279 .421,44}{4.011}$ & 568,29 & $\frac{6.801 .936,55}{4.011}$ & $1.695,82$ \\
\hline & Barra do Bugres & $\frac{13.923 .605,70}{32.490}$ & 428,55 & $\frac{31.295 .375,78}{32.490}$ & 963,23 \\
\hline & Nova Olímpia & $\frac{9.242 .560,72}{19.474}$ & 474,61 & $\frac{22.696 .676,27}{19.474}$ & $1.165,49$ \\
\hline & Denise & $\frac{3.042 .754,34}{10.349}$ & 294,01 & $\frac{7.780 .921,55}{10.349}$ & 751,85 \\
\hline & Santo Afonso & $\frac{2.319 .051,66}{2.855}$ & 812,28 & $\frac{5.291 .909,21}{2.855}$ & $1.853,56$ \\
\hline & Campo N. dos Parecis & $\frac{20.600 .855,06}{22.322}$ & 922,89 & $\frac{47.841 .518,96}{22.322}$ & $2.143,25$ \\
\hline & Brasnorte & $\frac{9.175 .840,17}{13.975}$ & 656,59 & $\frac{17.357 .457,46}{13.975}$ & $1.242,04$ \\
\hline & & Média & 572,48 & Média & $\overline{1.347,55}$ \\
\hline \multirow{8}{*}{2010} & Tangará da Serra & $\frac{54.154 .283,87}{81.918}$ & 661,08 & $\frac{106.386 .999,56}{81.918}$ & $1.298,70$ \\
\hline & Porto Estrela & $\frac{4.014 .976,39}{3.635}$ & $1.104,53$ & $\frac{8.704 .807,25}{3.635}$ & $2.394,72$ \\
\hline & Barra do Bugres & $\frac{20.407 .647,42}{29.847}$ & 683,74 & $\frac{42.260 .607,62}{29.847}$ & $1.415,91$ \\
\hline & Nova Olímpia & $\frac{15.921 .158,17}{17.135}$ & 929,16 & $\frac{30.753 .637,57}{17.135}$ & $1.794,78$ \\
\hline & Denise & $\frac{5.756 .178,19}{8.205}$ & 701,55 & $\frac{11.374 .419,55}{8.205}$ & $1.386,28$ \\
\hline & Santo Afonso & $\frac{3.139 .099,18}{2.737}$ & $1.146,91$ & $\frac{6.876 .449,46}{2.737}$ & $2.512,40$ \\
\hline & Campo N. dos Parecis & $\frac{29.358 .500,90}{26.577}$ & $1.104,66$ & $\frac{58.722 .645,39}{26.577}$ & $2.209,53$ \\
\hline & Brasnorte & $\frac{14.866 .781,10}{14.825}$ & $1.002,82$ & $\frac{27.986 .065,00}{14.825}$ & $1.887,76$ \\
\hline & & Média & 916,81 & Média & $1.862,51$ \\
\hline
\end{tabular}

* Despesa Total: Exceto Intra-Orçamentária

** Receita Total: Exceto Intra-Orçamentária, deduzido Contribuição FUNDEB.

*** No Habitantes: IBGE, Contagem da População 2007 e Censo 2010.

Fonte: Adaptado da Tabela 1 ano 2007 e Tabela 2 ano 2010 (Autor, 2012).

Analisando os dados de Zulian (2010), comparando a este trabalho, nota-se que as despesas com pessoal de Cachoeirinha-RS no ano de 2007 foram de $\mathrm{R} \$ 53.922 .763,48$ e com a população segundo o IBGE de 116.499 os gastos por habitante foram de R\$ 462,86 aproximadamente. 
No ano de 2010 Santo Afonso apresentou ser o município que mais investiu em despesa total com pessoal, no entanto, assim como o município de Denise, demonstrou também ter ocorrido redução na população em relação ao ano de 2007. Tangará da Serra por sua vez, revelou ter a menor DTP por habitante neste período $\mathrm{R} \$ 661,08$, e diferentemente da maioria dos outros municípios revelou ter aumentado sua população, sendo o acréscimo de 5.261. A média de gastos da região em 2010 foi de $\mathrm{R} \$ 916,81$, Denise esteve abaixo $\mathrm{R} \$$ 215,26 e Tangará da Serra R $\$ 255,73$, ou seja, 23,48\% e 27,89\% respectivamente.

\section{CONSIDERAÇÕES FINAIS}

Ao longo do desenvolvimento deste estudo, foi apresentada uma análise dos gastos com pessoal dos municípios da Região VIII, bem como comparações à obediência dos limites estabelecidos pela Lei de Responsabilidade Fiscal, a partir das informações publicadas no TCE-MT.

Considera-se que o problema desta pesquisa foi respondido por meio dos objetivos atingidos, que teve como objetivo geral em analisar as despesas com pessoal nos municípios de Denise e Tangará da Serra - MT, revelando como estiveram segundo os limites da LRF, que por sua vez demonstrados de acordo com os objetivos específicos alcançados em: a) identificar o comprometimento da Receita Corrente Líquida (RCL) com relação aos gastos com pessoal; b) verificar a situação de gastos com pessoal nos municípios em relação à LRF e; c) comparar as despesas com pessoal do município de Denise e Tangará da Serra - MT com a média de gastos da região VIII.

Portanto, a hipótese 1 de que os gastos com pessoal auferidos nos municípios de Denise e Tangará da Serra - MT estiveram na média de gastos da região, foi totalmente refutada pois Tangará sempre esteve acima da média da região, enquanto Denise esteve abaixo nos três primeiros períodos e acima da média no último. Já a hipótese 2 que foi levantada a saber se durante o período pesquisado Denise e Tangará da Serra - MT apresentaram abaixo do limite prudencial da LRF, foi validada apenas para o município de Denise, entretanto refutada para o município de Tangará que apresentou-se no ano de 2009 acima do limite prudencial e máximo.

Os resultados foram proporcionados através das tabelas, gráfico de evolução e análise. Conclui-se, portanto, que proporcionalmente às suas Receitas Correte Líquida, o município de Denise esteve com as despesas de pessoal abaixo da média da região durantes os três 
primeiros anos, e não apresentou ter maior comprometimento do que Tangará da Serra que sempre esteve acima da média da região durante o período pesquisado.

O comprometimento médio da RCL da região evoluiu 6,89 pontos percentuais de 2007 para 2010, o município de Denise evoluiu 11,50 pontos percentuais e Tangará da Serra 7,12. Analisando a evolução da despesa total com pessoal de Denise nos anos de 2007 a 2010 o aumento foi de $89,18 \%$ enquanto a RCL foi de apenas 46,18\%, no entanto Tangará da Serra evoluiu $63,17 \%$ e $43,80 \%$ respectivamente.

Proporcionalmente ao número de habitantes, conforme os censos do IBGE, o município de Denise - MT em 2007 e Tangará da Serra - MT em 2010, na região VIII deste estado, foram os municípios que menos comprometeram suas receitas corrente líquidas com despesas com pessoal, embora Tangará em 2009 tenha ultrapassado o limite máximo da LRF.

Sendo assim foi possível observar que as despesas com pessoal do município de Denise-MT tiveram uma evolução significativa, e somente no ano de 2010 atingiu o limite alerta, o que talvez possa justificar a impossibilidade de ajustes salariais aos professores, mas que não pode ser confirmado devido à abrangência deste estudo.

Contudo, permanecerá em aberto o espaço para novas pesquisas voltadas ao assunto, ou até mesmo a continuidade desta, a fim de compará-la diante de novos resultados das mais diversas regiões do estado de Mato Grosso ou do Brasil. Ainda poderá ser tratado em estudo mais aprofundado, a terceirização no setor público. Quanto às próximas gestões das prefeitura, ficam as expectativas de administração justa condizente com a realidade financeira de cada município e melhor condução possível dos recursos em benefício à coletividade.

\section{REFERÊNCIAS}

ANDRADE, Maria Margarida de. Introdução à metodologia do trabalho científico: elaboração de trabalhos na graduação. - 10. ed. - São Paulo: Atlas, 2010.

ANDRADE, Nilton de Aquino. Contabilidade pública na gestão municipal. São Paulo: Atlas, 2002.

BEZERRA FILHO, João Eudes. Contabilidade pública: teoria, técnica de elaboração de balanços e 300 questões. - Rio de Janeiro: Elsevier, 2005.

BRASIL. Constituição (1988). Constituição da República Federativa do Brasil. Diário Oficial [da] República Federativa do Brasil. Brasília, DF: Senado, 1988. 
Lei Complementar $\mathrm{n}^{\circ}$. 101, de 04 de maio de 2000. Estabelece normas de finanças públicas voltadas para a responsabilidade na gestão fiscal. Diário Oficial [da] República Federativa do Brasil. Brasília, 2000.

Lei $\mathbf{n}^{\circ}$. 4.320, de 17 de março de 1964. Estatui Normas Gerais de Direito Financeiro para Elaboração e Controle dos Orçamentos e Balanços da União, dos Estados, dos Municípios e do Distrito Federal. Diário Oficial da União, Poder Executivo, Brasília, DF, 23.03.1964.

Secretaria do Tesouro Nacional. Manual de demonstrativos fiscais: aplicado à União e aos Estados, Distrito Federal e Municípios: relatório de gestão físcal / Ministério da Fazenda, Secretaria do Tesouro Nacional. - 3. ed. - Brasília: Secretaria do Tesouro Nacional, Coordenação-Geral de Contabilidade, 2010.

CASTRO, Róbison Gonçalves de; LIMA, Diana Vaz de. Contabilidade pública: integrando União, Estados e Municípios (Siafi e Siafem). - 2. ed. - São Paulo: Atlas, 2003.

CLEMENTE, Ademir; GERIGK, Willson; TAFFAREL, Marinês. O comportamento das despesas públicas orçamentárias nos municípios brasileiros de porte médio. In: CONGRESSO INTERNACIONAL DE ADMINISTRAÇÃO, 22., 2010, Paraná. Anais eletrônicos... Paraná: ADMPG, 2010. Disponível em: <http://www.admpg.com.br/2010/selecionados.php>. Acesso em: 13 set. 2011.

CONGRESSO CONTABILIDADE UFSC. A evolução das despesas com pessoal no município de videira (SC) e sua observância aos limites desde a implantação da lei de responsabilidade fiscal. In: CONGRESSO DE CONTROLADORIA E FINANÇAS DA UFSC. 3., 2009, Florianópolis. Anais eletrônicos... Florianópolis: UFSC, 2009. Disponível em: < http://dvl.ccn.ufsc.br/congresso/anais/3CCF/20090730200918.pdf >. Acesso em: 10 out. 2011.

DEBUS, Ilvo; NASCIMENTO, Edson Ronaldo. Lei complementar $\mathbf{n}^{\mathbf{0}}$ 101/2000: entendendo a Lei de Responsabilidade Fiscal. -2. ed. 2011. Disponível em:

<http://www.tesouro.fazenda.gov.br/hp/downloads/EntendendoLRF.pdf $>$. Acesso em: 12 out. 2011.

DIAS, Fernando Álvares Correia. Textos para discução: o controle institucional das despesas com pessoal. Brasília, n.54, fev. 2009. Disponivel em :

<http://www.senado.gov.br/senado/conleg/textos_discussao.htm>. Acesso em: 10 set. 2011.

FARIAS, Sueli. Composição e evolução das despesas orçamentárias do município de Florianópolis no período de 2003 a 2008. Santa Catarina, 2009. Disponível em: < http://tcc.bu.ufsc.br/Contabeis291509>. Acesso em: 12 out. 2011.

HELENA, Eber Zoehler Santa. Controle dos gastos com pessoal pelo Congresso Nacional. Jus Navigandi, Teresina, ano 10, n. 1140, 15 ago. 2006. Disponível em:

< http://jus2.uol.com.br/doutrina/texto.asp?id=8805 >. Acesso em: 09 set. 2011.

KOHAMA, Heilio. Contabilidade pública: teoria e prática. -9. ed. - São Paulo: Atlas, 2003. . - 10. ed. - São Paulo: Atlas, 2006. 
LUCHI, Paulo Roberto; SANTOS, Hudson dos. A importância do controle interno sob enfoque da despesa com pessoal no âmbito municipal. In: CONGRESSO INTERNACIONAL DE CUSTOS, 9., 2005, Florianópolis. Anais eletrônicos... Florianópolis: IIC, 2005.

Disponível em: < www.intercostos.org/documentos/custos 500.pdf $>$. Acesso em: 10 out. 2011.

MORAES, Alexandre de. Direito constitucional. - 22. ed. - São Paulo: Atlas, 2007.

NASCIMENTO, Edson Ronaldo. Administração pública no Brasil: política fiscal nos Estados após a Lei de Responsabilidade Fiscal. Brasília, 2008. Disponível em:< http://repositorio.bce.unb.br/bitstream/10482/1655/1/2008_EdsonRonaldoNascimento.pdf>. Acesso em: 11 mar. 2012.

PRESTES, Maria Luci de Mesquita. A pesquisa e a construção do conhecimento científico: do planejamento aos textos, da escola à academia. - 3. ed. rev. atual. e ampl. - São Paulo: Rêspel, 2005.

SILVA, José Afonso da. Curso de direito constitucional positivo. - 29. ed. - São Paulo: Malheiros, 2007.

SILVA, Lino Martins da. Contabilidade governamental: um enfoque administrativo. -7 . ed. - São Paulo: Atlas, 2004.

SLOMSKI, Valmor. Manual de contabilidade pública: um enfoque na contabilidade municipal, de acordo com a Lei de Responsabilidade Fiscal. -2. ed. - São Paulo: Atlas, 2003.

TRABALHADORES da educação de Denise entram em greve por tempo indeterminado. 24HorasNews. Cuiabá, 27 jun. 2009. Disponível em: <http://www.24horasnews.com.br/index.php?mat=295978 >. Acesso em: 08 mar. 2012.

ZONEAMENTO - Dados secundários. E-Mato Grosso - Secretaria de Estado de Planejamento e Coordenação Geral. Cuiabá, 24 de mar. 2012. Disponível em: http://www.seplan.mt.gov.br/html/internas.php?tabela=paginas\&codigoPagina=97. Acesso em: 24 mar. 2012.

ZULIAN, Letícia Maria. A lei de responsabilidade fiscal e as finanças públicas: um enfoque sobre os limites da despesa com pessoal na prefeitura de Cachoeirinha - RS. Rio Grande do Sul, 2010. Disponível em: < http://www.lume.ufrgs.br/handle/10183/25733>. Acesso em: 09 set. 2011. 